\title{
Design and Synthesis of Crystalline Carboxyl-terminated Polyester Resin
}

\author{
Xiufang YE, Jingxuan LIN, Dongchu CHEN*, Menglei CHANG, Hongyang WEI
}

\author{
School of Materials Science and Hydrogen Energy, Foshan University, Foshan 528000, Guangdong Province, China \\ crossref http://dx.doi.org/10.5755/j02.ms.24058
}

Received 19 August 2019; accepted 01 November 2019

\begin{abstract}
In this work, a novel semi-crystalline polyester resin synthesis was explored, then influence of alcohol/acid ratio and monomer's structure on crystallinity of poliester resin were studied in details. The crystalline polyester resin was synthesized via a two-step melt-condensation method. The structure and performance of the polyester resin was characterized by X-ray diffraction, infrared radiation, differential scanning calorimeter, thermogravimetric analysis and melt flow rate. The effect of molar ratio between alcohol monomer and carboxyl monomer on the structure and performance of polyester resin was studied, based on these, how the modifications (1,4-cyclohexanedicarboxylic acid and 1,4-cyclohexanedimethanol) affected the crystalline properties of the resin were further studied and optimized with the multi-factors orthogonal test method, and the results show that the synthesized polyester resin meets the expected design, and has some crystalline structure. The change of hydroxyl/carboxyl ratio $(-\mathrm{OH} / \mathrm{COOH})$ can affect the crystallinity: the larger the crystallinity, the smaller the melt flow rate. Two modifications containing rigid cyclohexyl groups with high symmetry can improve the crystallinity of polyester resin.

Keywords: molecular design, crystallinity, multi-factors orthogonal test method, optimization.
\end{abstract}

\section{INTRODUCTION}

Polyester-based coatings are an ideal powder paints due to their good weatherability, anti-corrosion, and decorative properties. Polyester resins are the main component of polyester powder paint for film formation, powder paint is usually prepared from amorphous polyester resin. Higher glass transition temperatures $(T \mathrm{~g})$ of the polyester resin results in better powder paint stability $[1,2]$. The $T g$ of the amorphous polyester resin was positively related to the melt viscosity [3-5], i.e., the higher the $T g$, the larger the melt viscosity of resin. However, high melt viscosity reduces the activity of the reaction between the resin and the curing agent [6]. Therefore, the polyester powder paint prepared via an amorphous polyester resin has disadvantages $[7,8]$ such as high curing temperature and the need for toxic 1,3,5triglycidyl isocyanurate as the curing agent-these limits the application of polyester powder paint.

Previous studies [9-11] showed that crystalline saturated carboxyl-terminated polyester resin reduces the melt viscosity of the polyester resin due to the existence of its crystalline structure. During the curing and crossover reaction, the crystalline structure can improve the curing reaction and effectively reduce the curing temperature of the polyester powder paint. In addition, the hydroxyalkylamide curing agent is compatible with saturated carboxyl-terminated polyester resin and this offers advantages including good safety and non-toxicity [12].

Current research on crystalline saturated carboxylterminated polyester resin has mainly focused on its applications. For example [11], UCB Inc. in Belgium reported the use of crystalline polyester resins for

\footnotetext{
${ }^{*}$ Corresponding author. Tel.: +86-757-82700525 fax: +86-757-

82700525. E-mail address:chendc@fosu.edu.cn (D. Chen)
}

modification of an acrylic copolymer in 1996, but did not discuss the synthesis method. In 2003, the same company reported mixed usage of an amorphous polyester and semicrystalline polyester, which can decrease the curing temperature of the prepared powder paint. However, the synthesis of crystalline polyester has still not been discussed. In addition, some patents related to powder paint based on crystalline polyester resins were published [13-15], but they lack a detailed synthesis method or details on the performance of the semi-crystalline polyester.

Based on this background, monomers that contain rigid group such as phenyl and cyclic compound were used to synthesize novel saturated carboxyl-terminated polyester resins from molecular designs. These were based on the activity difference of a monomer structure and its influence on flexibility and regularity. The structure of the resin was characterized along with the impact of monomer structure on resin crystallinity.

\section{EXPERIMENTS}

\subsection{Experiment principle}

Thermoset saturated carboxyl-terminated polyester resin was synthesized via a direct esterification and carboxylation process. The main monomers include polyol and polyacid. The reaction $[9,16-19]$ is shown below.

The hydroxyl-terminated polyester resin with a low degree of condensation was synthesized via esterification and a condensation reaction.

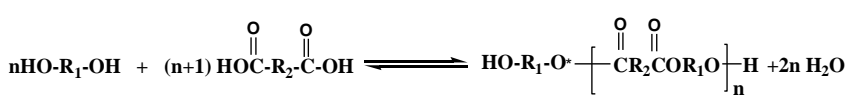

An acidifying agent was added to react with the aforementioned polyester resin with low degree of condensation to produce carboxyl-terminated polyester resin. 


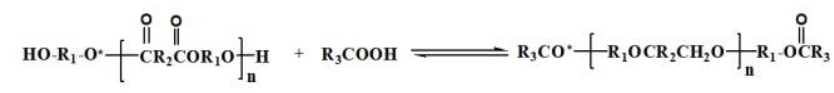

Here, $R_{1}$ is the monomer structure of the polyol, and $R_{2}$ is the monomer structure of polyacid; $R_{3}$ is the structure of the acidifying agent.

\subsection{Materials and instrumentation}

The raw material (all analytical grade) composition for polyester synthesis is shown in Table 1. The main instruments used in this investigation are listed in Table 2.

Table 1. Raw materials and agents for polyester synthesis

\begin{tabular}{|l|l|l|}
\hline \multicolumn{2}{|c|}{ Chemicals } & \multicolumn{1}{c|}{ Manufacturer } \\
\hline $\begin{array}{l}\text { Monomer } \\
\text { alcohol }\end{array}$ & Neopentyl glycol & Guoyao Chemicals Inc. \\
\hline $\begin{array}{l}\text { Monomer } \\
\text { acid }\end{array}$ & Terephthalic acid & Alading Chemicals Inc. \\
\cline { 2 - 3 } $\begin{array}{l}\text { Acidifying } \\
\text { agent }\end{array}$ & Trimellitic anhydride & Tokyo Chemicals Inc. \\
\hline $\begin{array}{l}\text { Thermo } \\
\text { stabilizer }\end{array}$ & Triphenyl phosphite & Guoyao Chemicals Inc. \\
\hline Catalyst & $\begin{array}{l}\text { Butylhydroxyoxo- } \\
\text { stannane }\end{array}$ & Alading Chemicals Inc. \\
\hline \multicolumn{2}{|c|}{ Potassium hydroxide } & Alading Chemicals Inc \\
\hline \multicolumn{2}{|c|}{ Methylbenzene } & Alading Chemicals Inc \\
\hline \multicolumn{2}{|c|}{ Acetone } & Alading Chemicals Inc \\
\hline \multicolumn{2}{|c|}{ Anhydrous ethanol } & Alading Chemicals Inc \\
\hline
\end{tabular}

Table 2. Instruments for polyester resin synthesis

\begin{tabular}{|l|l|}
\hline \multicolumn{1}{|c|}{ Instruments temperature- } & \multicolumn{1}{|c|}{ Manufacturer } \\
\hline $\begin{array}{l}\text { DZTW Yongguanming Medical } \\
\text { controlled electric jacket } \\
\text { Instruments Inc. }\end{array}$ \\
\hline $\begin{array}{l}\text { SHZ-D(III) recycled water } \\
\text { based vacuum pump }\end{array}$ & $\begin{array}{l}\text { Gongyi Yinyuyuhua Instruments } \\
\text { Inc. }\end{array}$ \\
\hline $\begin{array}{l}\text { Four-neck flask, condenser, } \\
\text { thermometer }\end{array}$ & $\begin{array}{l}\text { Guangzhou Jingke Glassware } \\
\text { Inc. }\end{array}$ \\
\hline $\begin{array}{l}\text { XJB 90-S Digital rotatory } \\
\text { blender }\end{array}$ & $\begin{array}{l}\text { Shanghai Standard Modeling } \\
\text { Factory }\end{array}$ \\
\hline $\begin{array}{l}\text { CS101-AB Electric heated air } \\
\text { dry oven }\end{array}$ & $\begin{array}{l}\text { Chongqing Instrument Test } \\
\text { Factory }\end{array}$ \\
\hline
\end{tabular}

\subsection{Synthesis method and process}

The detailed synthesis method of crystalline polyester resin includes the following steps as shown in Fig. 1.

(1) Esterification condensation
The alcoholic monomer and catalyst were added into a four-necked flask. After mixing, the system was heated to $130-135{ }^{\circ} \mathrm{C}$, and some acidic monomer was added and mixed and placed under $\mathrm{N}_{2}$. The system was heated to $230-235{ }^{\circ} \mathrm{C}$ to allow thermostatic reaction until the acid value was lower than $5 \mathrm{mg} \mathrm{KOH} / \mathrm{g}$. The system was then cooled to $170{ }^{\circ} \mathrm{C}$, and the remaining acid monomer (C) was added, and the system was heated to $235-240^{\circ} \mathrm{C}$. The system was kept heated until the acid value of system was $5-10 \mathrm{mg} \mathrm{KOH} / \mathrm{g}$. When $96 \%$ of the theoretical water was collected, a thermo-stabilizer was added into reaction system, and the vacuum was held at $700-750 \mathrm{mmHg}$ until the acid value of system was $5 \mathrm{mg} \mathrm{KOH} / \mathrm{g}$ (about $2-2.5 \mathrm{hr}$ ). The $\mathrm{N}_{2}$ was purged and produce hydroxylterminated polyester resin.

(2) Carboxylation

The system was cooled to $170{ }^{\circ} \mathrm{C}$ and treated with an acidifying agent. The temperature was gradually raised to $235-240{ }^{\circ} \mathrm{C}$. When the acid value of system was

$20-35 \mathrm{mg} \mathrm{KOH} / \mathrm{g}$, the vacuum condensation was repeated (about $30 \mathrm{~min}$ ). The system was then cooled and discharged to obtain a polyester resin product.

\subsection{Test and characterization}

The structure of crystalline carboxyl-terminated polyester resin were detected with the following analytical techniques.

Fourier-transform infrared spectroscopy was used to characterize the structure of resin (manufacture: Nicolet, Type: FTIR-850, measuring range: from $4000 \mathrm{~cm}$ to $1-400 \mathrm{~cm}^{-1}$, accuracy: $0.01 \mathrm{~cm}^{-1}, \mathrm{KBr}$ pellet pressing method).

The polyester resin was ground into a fine powder, and the XRD powder diffraction test was conducted. Based on the XRD pattern, the state of the crystal in the resin sample was analyzed. The crystallinity was calculated by Jade software based on the XRD pattern [20, 21].

A thermogravimetric method was used to analyze the thermo-stability of the polyester resin. The instrument was STA 449C produced by NETZSCH Inc. in Germany. The test conditions were described as follows: 4-10 mg sample was placed on platinum pan; the sample was then heated from $40{ }^{\circ} \mathrm{C}$ to $600{ }^{\circ} \mathrm{C}$ under $\mathrm{N} 2$ atmosphere with $40 \mathrm{~mL} / \mathrm{min}$ flow rate. The heating rate was $10^{\circ} \mathrm{C} / \mathrm{min}$.

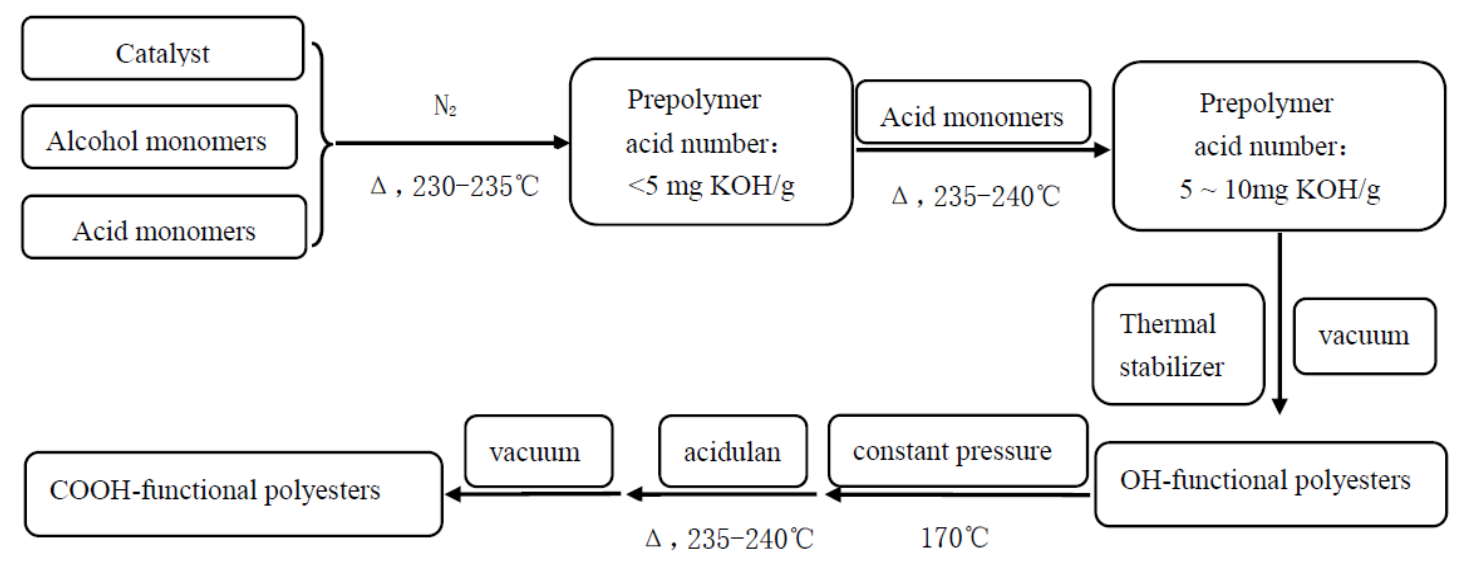

Fig. 1. Synthesis process of crystalline polyester resin 
Universal V1.717 TA Instruments DSC2910 were used for differential scanning calorimetry (DSC). The testing temperature range was -80 to $200^{\circ} \mathrm{C}$. The temperature of system was increasing to $200^{\circ} \mathrm{C}$ at $10^{\circ} \mathrm{C} / \mathrm{min}$, and kept at $200^{\circ} \mathrm{C}$ for $10 \mathrm{~min}$, and then cooled down at $10^{\circ} \mathrm{C} / \mathrm{min}$. The atmosphere was $\mathrm{N}_{2}$.

The melt flow rate of the polymer was defined as the weight of polymer melt that flows through the standard capillary with a specific diameter and length every $10 \mathrm{~min}$. This was represented in the MFR (unit: g/10 min). According to ASTM standard D1238-04, the melt flow indexer (MFR-M) from Shijiazhuang Laboratory instrument factory was used to measure the MFR of the test sample.

The detailed measurement of carboxyl-terminated polyester resin was referred to HG/T2708-95. During measurement, an appropriate sample was placed in a 250 $\mathrm{mL}$ flask, and 20-30 mL acetone/alcohol mixture was added. The flask was shaken until the sample was completely dissolved. Then, a small amount of phenolphthalein indicator was added, and $0.1 \mathrm{~mol} / \mathrm{L}$ $\mathrm{KOH} /$ alcohol standard solution was used for titration until the solution became red for at least $30 \mathrm{~s}$. A blank sample served as the control. The result was defined as the arithmetic mean value from two parallel experiments with two significant digits. The acid value $X$ was calculated according to the Eq. 1:

$X=\frac{\left(\mathrm{V}_{1}-V_{2}\right) \bullet C \times 56.1}{m}$,

where $X$ is acid value in $\mathrm{mg} \mathrm{KOH} / \mathrm{g} ; V_{1}$ is the titration usage of $\mathrm{KOH} /$ alcohol standard solution, in $\mathrm{mL} ; V_{2}$ is the titration usage of $\mathrm{KOH} /$ alcohol standard solution in $\mathrm{mL}$; $C$ is the concentration of $\mathrm{KOH} /$ alcohol standard solution for titration in $\mathrm{mol} / \mathrm{L}$; and $\mathrm{m}$ is the weight of test sample in $\mathrm{g}$.

\section{RESULTS AND DISCUSSION}

\subsection{Molecular design of crystalline polyester resin}

The structure of the monomer is a vitally important factor on resin aggregation. To transform the aggregation state of the polyester from an amorphous state to a semicrystalline state, an appropriate monomer needs to be selected based on the influence of structure on polymer performance [1, 22-23]. Monomers that contain a rigid unit to induce a crystal usually form regularly arranged aggregates more easily. The existence of this ordered structure was represented as a crystal in the macro state.

Based on this principle, terephthalic acid, hexanedioic acid, neopentyl glycol were selected as monomers for the synthesis of carboxyl-terminated polyester resin. Neopentyl glycol and terephthalic acid both have a symmetrical structure and more easily produce clear crystals, which are the basic structural segment of crystalline polyester. In the meanwhile, these two monomers are not only cheap, but are also advantageous to improving the hardness and abrasive resistance of the coating. Hexanedioic acid offers flexibility and an appropriate $T \mathrm{~g}$ to polyester resin. However, hexanedioic acid can compete with terephthalic acid to generate complex long chains because the reactivity ratio of the terephthalic acid is much lower than hexanedioic acid. This affects the crystallinity of the resin. To avoid the negative effects of hexanedioic acid on the crystallization property, hexanedioic acid was added to continue the esterification reaction only when the terephthalic acid was nearly completely reacted.

In summary, direct esterification was used with terephthalic acid, hexanedioic acid, and neopentyl glycol. The polyester resin shown in Fig. 2 was synthesized through a two-step process including esterification and carboxylation. Further XRD resin analysis will indicate whether the aggregates are crystalline or amorphous.

\subsection{Structure characterization and performance test of crystalline polyester resin}

The polyester resin shown in Fig. 2 was synthesized via a two-step melt esterification method using trimellitic anhydride as the acidifying agent for terephthalic acid, hexanedioic acid, neopentyl glycol monomers. The synthesized polyester resin was characterized and its performance features were tested.

The synthesized polyester resin was characterized by infrared spectroscopy (Fig. 3). The peak at $1735 \mathrm{~cm}^{-1}$ is attributed to the stretching mode of the $\mathrm{C}=\mathrm{O}$ conjugated system. The peak at $1714 \mathrm{~cm}^{-1}$ is the stretching vibration of the $\mathrm{C}=\mathrm{O}$ saturated aliphatic ketone. The peaks at 1105 and $1017 \mathrm{~cm}^{-1}$ are attributed to the symmetrical stretching of the COO- carboxyl group. The peak at $730 \mathrm{~cm}^{-1}$ is the bending vibration of COO-.

IR analysis is listed as below: $2969\left(\mathrm{~m}, v_{\mathrm{C}-\mathrm{H}},-\mathrm{CH}_{3}\right)$, $1735\left(\mathrm{~s}, v_{\mathrm{C}}=\mathrm{O}_{\mathrm{O}}\right.$, $\left(\mathrm{w}, v_{\mathrm{c}=\mathrm{c}}, \quad>\right), 1504\left(\mathrm{w}, \delta_{\mathrm{O}-\mathrm{H}}\right), 1473-1408\left(\mathrm{w}, \delta_{\mathrm{C}-\mathrm{H},}-\right.$ $\left.\mathrm{CH}_{2-}\right), 1376\left(\mathrm{~m}, \delta_{\mathrm{C}-\mathrm{H}},-\mathrm{CH}_{3}\right), 1269$ (s, $\left.v_{\mathrm{C}-\mathrm{O}-\mathrm{C}}\right), 1105,1017(\mathrm{~s}$,

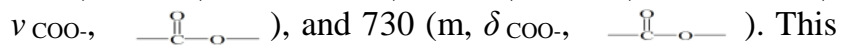
analysis shows that all expected functiona groups are present.

The resin powder was characterized by XRD to determine whether this novel carboxyl-terminated polyester resin is crystalline or amorphous. The XRD pattern is shown in Fig. 4. The sample has a sharp peaks at $17.5^{\circ}, 25.2^{\circ}$, and $27.6^{\circ} 2 \theta$ indicating that this polyester resin has obvious crystalline structure [24].

The crystallinity to amorphous structure ratio was calculated at $8.9 \%$ by Jade software based on the peak separation method.

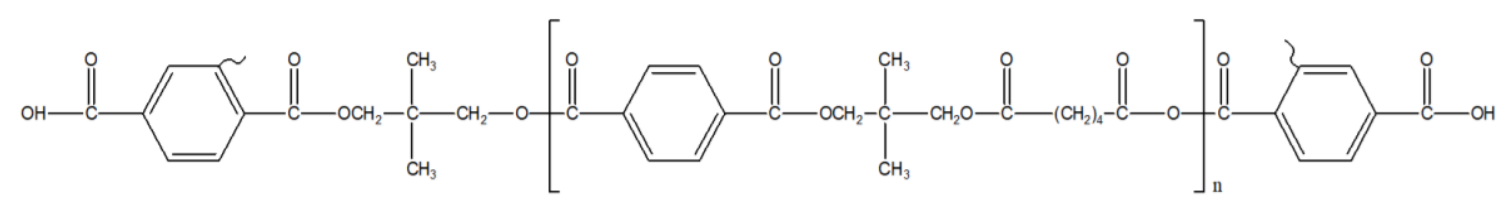

Fig. 2. Characteristic structure of novel carboxyl-terminated polyester resin 


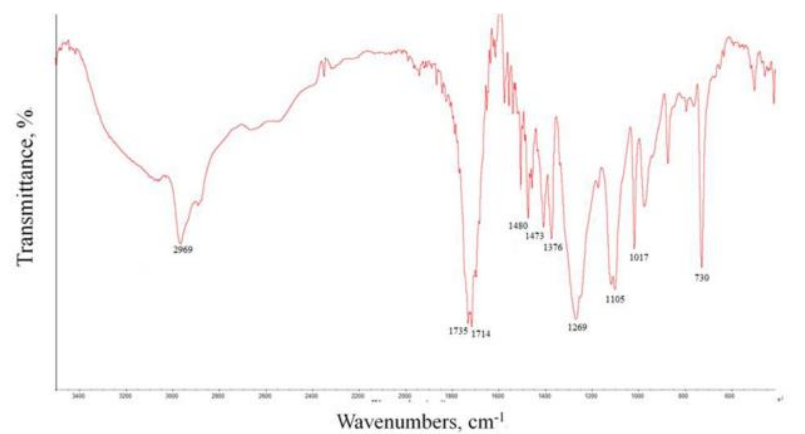

Fig. 3. Infrared transmission spectrum of novel carboxylterminated polyester resin

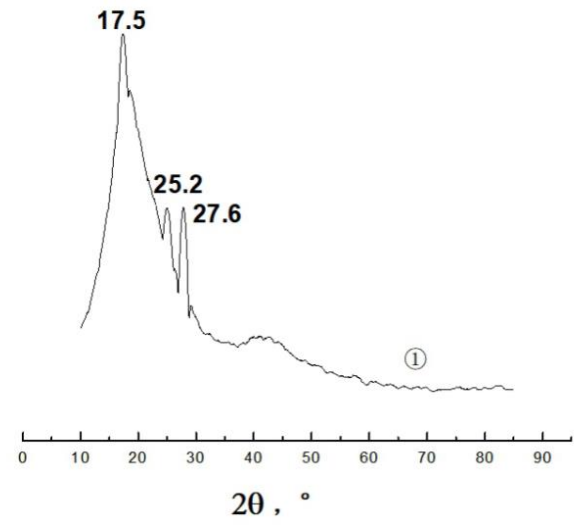

Fig. 4. The XRD pattern of polyester resin

The glass transition temperature of the polyester resin is an important indicator, which indicates the stability of the powder paint during storage. The general requirement of $\mathrm{Tg}$ is between 50 and $55^{\circ} \mathrm{C}$. Fig. 5 is the DSC curve of novel carboxyl-terminated polyester resin. Using the double tangent method, the glass transition temperature $(\mathrm{Tg})$ is greater than $55{ }^{\circ} \mathrm{C}$ indicating good stability of this novel carboxyl-terminated polyester resin during storage and transportation.

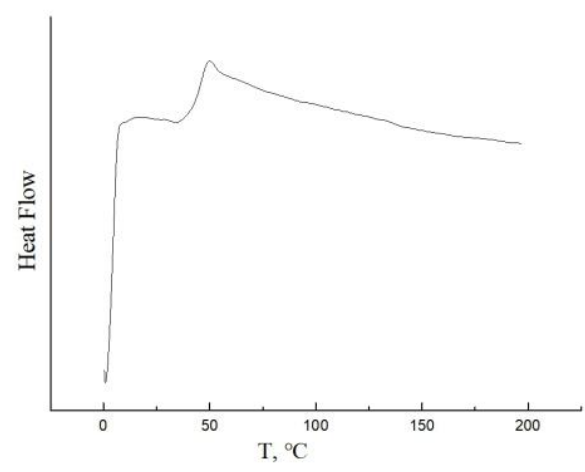

Fig. 5. DSC measurement of semi-crystalline polyester

Generally speaking, a semi-crystalline resin can show two $T \mathrm{~g}$ peaks in the DSC curve due to the amorphous region that can freely move or other amorphous regions that are limited by adjacent crystalline regions. Two peaks can be seen from the DSC curve of the polyester resin. This shows the characteristics of the semi-crystalline polyester. This result shows that the resin has a crystalline structure [25].
TG measured the performance of the novel polyester resin. The TG curve is shown in Fig. 6, which shows that the polyester resin had weight loss from room temperature to $257.4{ }^{\circ} \mathrm{C}$, but this was only minor. From

$257.4-461.3{ }^{\circ} \mathrm{C}$, the sample was in a continuous weight loss state and plateaued again in $461.3-600^{\circ} \mathrm{C}$. The curve showed that the decomposing temperature of the polyester resin was $257.4{ }^{\circ} \mathrm{C} ; \quad 461.3{ }^{\circ} \mathrm{C}$ was the terminal temperature. The synthesized polyester has good thermostability.

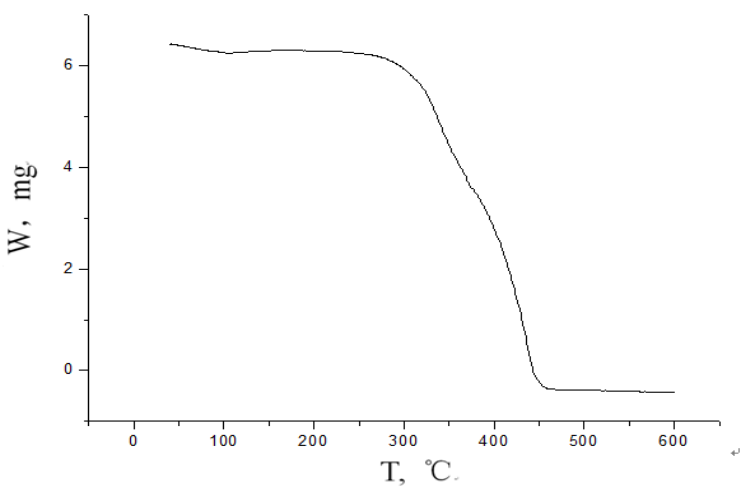

Fig. 6. TG analysis of semi-crystalline polyester

\subsection{Effect of the alcohol/acid ratio to the crystallinity of polyester resin}

In two-step process, the hydroxyl-terminated polyester molecule was produced first, and then the carboxyl-terminated polyester resin was synthesized via esterification. The hydroxyl/carboxyl ratio $(-\mathrm{OH} /-\mathrm{COOH})$ needs to be controlled to ensure that the reaction has proceeded as expected. In principle, the amount of carboxyls should be greater than the number of hydroxyls in the entire reaction to produce carboxyl-terminated resin. However, because the first step is to obtain hydroxylterminated polyester resin, the use of hydroxyl is greater than that of carboxyl due to two reasons. The first is to make sure that the synthesized polyester is hydroxyl terminated. The second is to consider the alcohol loss during reaction because the boiling point of alcohol is greater than that of acid. Table 3 shows the ratio between reacted alcohol (neopentyl glycol(A)) and acid (terephthalic acid (B), hexanedioic acid (C), and trimellitic anhydride (D)) during the synthesis of crystalline polyester.

Table 3. Hydroxyl and carboxyl monomer mol ratio amount for crystalline polyester resin preparation

\begin{tabular}{|c|c|c|}
\hline Reaction stage & $\begin{array}{c}\text { mol ratio of } \\
\text { Hydroxyl/carboxyl } \\
(-\mathrm{OH} /-\mathrm{COOH})\end{array}$ & Value \\
\hline $\begin{array}{c}\text { Entire reaction } \\
\text { (condensation }+ \\
\text { carboxylation) }\end{array}$ & (A)/ (B+C+D) & $1: 1.038-1.044$ \\
\hline Condensation & (A)/ $(\mathrm{B}+\mathrm{C}+\mathrm{D})$ & $1.034-1.040: 1$ \\
\hline
\end{tabular}

According to the reactants given in Table 4, the polyester resin was synthesized based on the method described in section 2.3 under different hydroxyl/carboxyl mol ratios. 
Table 4. Hydroxyl and carboxyl monomer amount for crystalline polyester resin preparation

\begin{tabular}{|c|c|c|c|}
\hline \multirow[b]{2}{*}{$\begin{array}{l}\text { Sample } \\
\text { number }\end{array}$} & \multicolumn{2}{|c|}{ mol ratio of Hydroxyl/carboxyl } & \multirow[b]{2}{*}{ Crystallinity } \\
\hline & $\begin{array}{l}\text { in entire reaction } \\
(\mathrm{A}) /(\mathrm{B}+\mathrm{C}+\mathrm{D})\end{array}$ & $\begin{array}{l}\text { in condensation } \\
\text { reaction } \\
(\mathrm{A}) /(\mathrm{B}+\mathrm{C}+\mathrm{D}) \\
\end{array}$ & \\
\hline (2) & $1: 1.038$ & $1.034: 1$ & 6.8 \\
\hline (3) & $1: 1.041$ & $1.037: 1$ & 11.1 \\
\hline (4) & $1: 1.044$ & 1.040:1 & 9.3 \\
\hline
\end{tabular}

Fig. 7 shows the XRD pattern of the three samples of polyester resin synthesized under different hydroxyl/carboxyl ratios as given in the table 4 . Diffraction peaks appeared at $17.2^{\circ}, 24.8^{\circ}$ and $28.6^{\circ}$ diffraction angles. The existence of crystalline structure in the polyester resin can be determined based on the position of the sharp peak according to literatures [25]. The crystallinity to amorphous structure ratio of the polyester resin synthesized via three different hydroxyl/carboxyl ratios were $6.8 \%, 11.1 \%$ and $9.3 \%$ accordingly. When the hydroxyl/carboxyl ratio in condensation reaction was controlled at 1.037 , i.e., the hydroxyl/carboxyl ratio in overall reaction was 1:1.041, the semi-crystalline polyester resin has the largest crystallinity at $11.1 \%$.

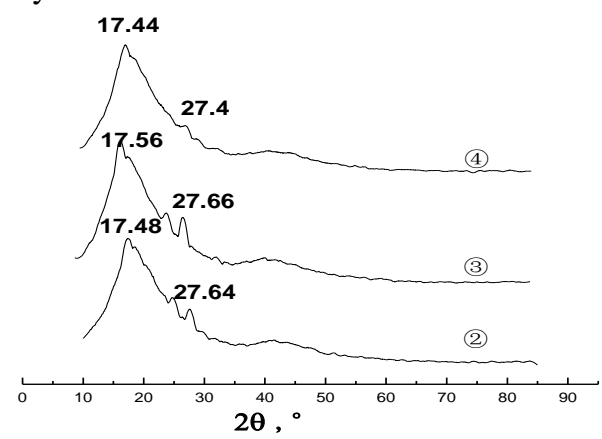

Fig. 7. X-ray spectrum of polyester resin under three different hydroxyl/carboxyl ratios: (2) - 1:1.038; (3) - 1:1.041; (4) $-1: 1.044$

\subsection{Melt flow rate analysis on polyester resin}

The melt flow rate of the crystalline resin sample was measured to clarify the relationship between melt viscosity and crystallinity of the resin (Table 5). The crystallinity and melt flow rate showed the same trend, indicating that they are positively correlated, i.e., the higher the crystallinity, the larger the melt flow rate. The melt flow rate of resin is also positively correlated with melt viscosity [23-24]. This result further proves that higher crystallinity percentage values result in lower the melt viscosity and higher reactivity between resin and curing agent. This reduces the curing temperature of the prepared powder paint.<smiles>[Z6]c1cc(C(=O)O)ccc1C(=O)C(C)(C)OC(=O)C1CCC(C(=O)OCC(C)(C)OC(=O)c2ccc(C(C)(C)OCC(C)(C)OC(=O)c3ccc(C(=O)O)cc3SS)cc2)CC1</smiles>

Table 5. Melt flow rate of polyester resin samples

\begin{tabular}{|c|c|c|c|c|}
\hline Sample number & 1 & (2) & (3) & (4) \\
\hline MFR, g/10 min & 3.15 & 3.60 & 4.05 & 3.82 \\
\hline Crystallinity, \% & 8.9 & 6.8 & 11.1 & 9.3 \\
\hline
\end{tabular}

\subsection{Modifications in the crystalline structure of polyester resin}

Our results therefore showed that it was possible to use direct esterification to prepare a carboxyl-terminated polyester resin with a crystalline structure by controlling the alcohol-to-acid ratios and identifying diols/polyols and dicarboxylic acids/polyacids that have symmetrical structures and contained rigid, crystal-inducing units. To further explore the effects of monomer structure on the crystallization properties of the resin, we introduced 1,4-cyclohexanedicarboxylic acid (CHDA) and 1,4-cyclohexanedimethanol (CHDM), two monomers containing rigid cyclohexyl groups with high symmetry, into the polyester resin. This allowed us to study the modifications of the polyester resin and to explore how the addition of these monomers affected the crystalline properties of the resin (Fig. 8).

\subsubsection{Effect of CHDM on the crystallization properties of the polyester resin}

CHDM imparts high chemical reactivity and weatherability to polyester [1]. In addition, its highly symmetrical structure improves the regularity of the polyester molecular chain, prompting the ester to form a crystalline structure. Based on the previously identified effect of the alcohol-to-acid ratio on the resin crystallinity, we maintained the alcohol-to-acid ratio of the total reaction at 1:1.041 and the alcohol-to-acid ratio of the polycondensation reaction at $1: 1.1037$. We also partially replaced neopentyl glycol (A) with CHDM (E) to stimulate esterification. Crystalline polyester resin was prepared as described in section 2.3; the crystallinity of the resin was determined and calculated with XRD powder diffraction as described in section 2.4. The crystallinities of modified polyester resins obtained at different CHDM (E) concentrations are shown in Table 6.

Table 6. Crystallinity data of CHDM-modified semi-crystalline polyester resins

\begin{tabular}{|c|c|c|}
\hline $\begin{array}{c}\text { Sample } \\
\text { number }\end{array}$ & $\begin{array}{c}\text { Molar percentage of CHDM in } \\
\text { the alcohol component, } \% \\
\text { E/ (A + E) }\end{array}$ & $\begin{array}{c}\text { Crystallinity, } \\
\%\end{array}$ \\
\hline 5 & 3.0 & 18 \\
\hline 6 & 4.0 & 20 \\
\hline 7 & 5.0 & 19 \\
\hline
\end{tabular}

Fig. 8. Characteristic chemical structure of a novel modified carboxyl-terminated polyester resin 
When CHDM comprised $3 \%, 4 \%$, and $5 \%$ of the total alcohol concentration, the X-ray diffraction peaks of the polyester resin were observed at different diffraction angles $\left(3 \%\right.$ : $17.3-17.4^{\circ} ; 4 \%$ : $24.9-25.1^{\circ}$; and $5 \%$ : $27.8-28.1^{\circ}$; X-ray diffraction spectroscopy analysis confirming the presence of a crystal structure in the CHDM-modified carboxyl-terminated polyester resin. We used the peak separation method to calculate the crystallinity of the polyester resin at CHDM concentrations of $3 \%, 4 \%$, and $5 \%$. At these concentrations, the crystallinities of the polyester resin were $18 \%, 19 \%$, and $18 \%$, respectively, all of which were higher than the crystallinity of the unmodified polyester resin $(<11.1 \%)$. Therefore, our results indicate that the addition of CHDM increased the crystallization of the polyester resin.

\subsubsection{Effect of CHDA on the crystallization properties of the polyester resin}

The highly active monomer CHDA improves the chemical and physical properties of polyester, increasing its hardness, toughness, weatherability, and hydrolysis resistance. CDHA also imparts anti-yellowing effects [1]. In addition, the symmetrical structure of CHDA increases the regularity of the polyester molecular chain, promoting the formation of crystal structures. Based on the previously identified effect of the alcohol-to-acid ratio on the resin crystallinity, we controlled the alcohol-to-acid ratio of the total reaction at 1:1.041 and the alcohol-to-acid ratio of the polycondensation reaction at 1:1.1037. We added CHDA (F) to stimulate esterification. Crystalline polyester resin was prepared as described in section 2.3 ; the crystallinity of the resin was determined and calculated with XRD powder diffraction as described in section 2.4 (2). The crystallinities of modified polyester resins obtained at different CHDM (F) concentrations are shown in Table 7.

Table 7. Crystallinity data of CHDA-modified semi-crystalline polyester resins

\begin{tabular}{|c|c|c|}
\hline $\begin{array}{c}\text { Sample } \\
\text { number }\end{array}$ & $\begin{array}{c}\text { Molar percentage of CHDA } \\
\text { in the acid component, } \% \\
\mathrm{~F} /(\mathrm{A}+\mathrm{B}+\mathrm{C}+\mathrm{F})\end{array}$ & $\begin{array}{c}\text { Crystallinity, } \\
\%\end{array}$ \\
\hline 8 & 2.5 & 18 \\
\hline 9 & 3.0 & 20 \\
\hline 10 & 3.5 & 19 \\
\hline
\end{tabular}

When the molar percentage of CHDA in the acid component was $2.5 \%, 3.0 \%$, or $3.5 \%$, the crystallinity of polyester resin was $18 \%, 20 \%$, or $19 \%$, respectively, higher than the crystallinity of the unmodified polyester resin $(<11.1 \%)$. Our results thus strongly suggest that CHDA promotes crystallization in the new polyester resin.

\subsubsection{Optimization of the concentrations of CHDM and CHDA}

Our single-factor analyses indicated that CHDM and CHDA promote the crystallization of the polyester resin. We therefore altered the concentrations of CHDM and CHDA used in the crystallization process. The concentrations of each monomer were optimized with a two-factor, three-level orthogonal experiment (Table 8, Table 9).
All samples had diffraction peaks at the diffraction angles of $18^{\circ}, 25^{\circ}$, and $28^{\circ}$ according to the X-ray diffraction spectroscopy analysis.

Table 8. Levels of the factors in the orthogonal experiment

\begin{tabular}{|c|c|c|}
\hline \multirow{2}{*}{ Level } & \multicolumn{2}{|c|}{ Factor } \\
\cline { 2 - 3 } & $\begin{array}{c}\text { Molar percentage of } \\
\text { CHDA in the acid } \\
\text { component, \% E }\end{array}$ & $\begin{array}{c}\text { Molar percentage of } \\
\text { CHDM in the alcohol } \\
\text { component, \% BF }\end{array}$ \\
\hline 1 & 2.50 & 3.00 \\
\hline 2 & 3.0 & 4.00 \\
\hline 3 & 3.50 & 5.00 \\
\hline
\end{tabular}

The sharp peak positions suggested that crystallinity was present in all synthesized polyester resins. The crystallinities of the polyester resin samples in the orthogonal experiments (11) - (19) ranged from 20 to $24 \%$ (Table 9), and, in every orthogonal experiment, the crystallization performance was better than that of the unmodified polyester resin sample. The highest polyester resin crystallinity (24\%) was observed when the ratio of CHDA to CHDM was E3F2 (orthogonal experiment (16)).

Table 9. Design of the orthogonal experiments

\begin{tabular}{|c|c|c|c|}
\hline $\begin{array}{c}\text { Sample } \\
\text { number }\end{array}$ & CHDM, & CHDA, g & $\begin{array}{c}\text { Crystallinity } \\
\text { percentage }\end{array}$ \\
\hline$(11)$ & $\mathrm{E}_{1}$ & $\mathrm{~F}_{1}$ & 20 \\
\hline 12 & $\mathrm{E}_{2}$ & $\mathrm{~F}_{1}$ & 21 \\
\hline 13$)$ & $\mathrm{E}_{3}$ & $\mathrm{~F}_{1}$ & 22 \\
\hline 14 & $\mathrm{E}_{1}$ & $\mathrm{~F}_{2}$ & 23 \\
\hline$(15)$ & $\mathrm{E}_{2}$ & $\mathrm{~F}_{2}$ & 22 \\
\hline 16 & $\mathrm{E}_{3}$ & $\mathrm{~F}_{2}$ & 24 \\
\hline$(17)$ & $\mathrm{E}_{1}$ & $\mathrm{~F}_{3}$ & 22 \\
\hline 18 & $\mathrm{E}_{2}$ & $\mathrm{~F}_{3}$ & 23 \\
\hline 19 & $\mathrm{E}_{3}$ & $\mathrm{~F}_{3}$ & 21 \\
\hline
\end{tabular}

\section{CONCLUSIONS}

1. In the view of molecular design, monomers with structurally symmetrical and rigid unit were selected to synthesize a polyester resin with a defined crystalline structure;

2. The crystallinity to amorphous structure ratio of the polyester resin was affected by the hydroxyl/carboxyl mol ratio, when the hydroxyl/carboxyl ratio in condensation reaction was controlled at 1.037 , i.e., the hydroxyl/carboxyl ratio in overall reaction was $1: 1.041$, the semi-crystalline polyester resin has the largest crystallinity at $11.1 \%$;

3. The addition of CHDM and CHDA promoted the crystallization of polyester resins. Our orthogonal experiments showed that the crystallinity to amorphous structure ratio of the polyester resin product increased to $24 \%$ when the molar percentage of CHDA in the acid component was $3.5 \%$ and the molar percentage of CHDM in the alcohol component was $4.0 \%$;

4. The results of X-ray diffraction spectroscopy and melt flow rate tests shown that higher crystallinity to amorphous structure ratio (higher crystallinity) produced better melt flowing ability of the crystalline carboxyl-terminated polyester resin, meanwhile, the 
higher glass transition temperature of the designed crystalline polyester, indicate that the formation of the crystalline structure may effectively reduce the melt viscosity while keep the high stability of the polyester powder paint system.

\section{Acknowledgments}

This work was financially supported by Foundation for Distinguished Young Talents in Higher Education of Guangdong, China (2015KQNCX178), Foshan Science and Technology Innovation Project (2020001004224) and Innovation and Strong School Project, Guangdong (2016GCZX008)

\section{REFERENCES}

1. Sheirs, J., Long, T.E. Modern Polyesters, Wiley, New York, 2005: pp. $267-292$.

https://doi.org/10.1002/0470090685

2. Yang, Z.Z., Xu, Y.Z., Zhao, D.L., Xu, M.J. Preparation of Waterborne Dispersions of Epoxy Resin by the PhaseInversion Emulsification Technique Colloid Polymer Science 2000: pp. 1164-1171. https://doi.org/10.1007/s003960000375

3. Stuck, M., Krenz, I., Schulze, K.B., Boye, S., Voit, B., Lorenz, R. Improving Glass Transition Temperature of Unsaturated Polyester Thermosets: Conventional Unsaturated Polyester Resins Journal of Applied Polymer Science 6 2020: pp. 138. https://doi.org/10.1002/app.49825

4. Sun, X.L. Prospects of the Development of Finishing and Proprietary Powder Coatings Modern Paint \& Finishing 24 (2) 2002: pp. 3-5.

https://doi:10.3969/j.issn.1007-9548.2002.01.002

5. Zhou, T., Xu, X.F., Fu, L.L. Polyester Resin and Powder Coating New Chemical Materials 29 (12)

2001: pp. $35-41$.

https://doi:10.3969/j.issn.1006-3536.2001.12.011

6. Melchiors, M., Sonatag, M., Kobusch, C., Jürgens, E. Recent Developments in Aqueous Two-component Polyurethane Progress in Organic Coatings 40 2000: pp. 99-109. https://doi.org/10.1016/S0300-9440(00)00123-5

7. Liu, G.J. The Modern Coating Process Technology. China Light Industry Press, Beijing, 2000: pp. 193-217.

8. Wen, N., Urethanized, B. Urethanized $\beta$ hydroxyalkylamide Compound, a Process for Preparing it and its Use for Preparing Powder Coating Materials, US 6342576, 2000: pp. 1-3.

9. He, T., Wang, L., Li, Y. A Low Light Powder Coating with Hybrid Polyester Resin and its Preparation Method, CN101205293A, 2008: pp. 1-2.
10. Wu, B. Sealing Side Containing Anhydride Crystalline Polyester Powder Coating Combination, CN1705697A, 2005: pp. 1-3.

11. Marc, V., Patrick, L., Daniel, M., Jean, M.L., Luc, M. Powder Compositions with Semicrystalline Polyester and Acrylic Copolymer Base Containing Ethylenically Unsaturate Groups, CN1234062A, 1999: pp. 1-3.

12. Graham, S., Harry, J.C. Method for Curing Polymers Containing One or More Carboxy or Anhydride Functions and Compositions, US4076917, 1978: pp. 1-3.

13. Werner, K., Hermann, G., Joachim, P. Aqueous Coating Composition Based on Specific Two-component Polyurethane and a Process for its Production, US5075370, 1991: pp. 1-2.

14. Nienhaus, E., Mayer, B., Mersenburg, U. Aqueous Twocomponent Polyurethane Coating Composition, Process for its Preparation, and its use in Processes for the Production of a Multicoat Finish, US5670600, 1997: pp. 1-5.

15. Weyland, P., Treiber, R.S.A., $\quad$ Seibert, H. Mixtures Containing Water-emulsifiable Isocyanates, US5587421, 1996: pp. $1-2$.

16. Al, G.H. Process for the Production of Polyester Resins, US6245863 B1, 2001: pp. 1-3.

17. Liu, Y.J., Li, B.C., Wu, D.Q. A Hybrid Polyester Resin Preparation Method, CN101143922A, 2008: pp. 1-2.

18. Chen, Z.T., Chen, L.C., Zhang, J. The Preparation Method of Weather Resistance of Powder Coatings with Polyester Resin, CN1296048A, 2001: pp. 1-3.

19. Liu, L., Gu, Y.X., Zhang, J. A Method of Preparation of Hybrid Powder Coatings with Polyester Resin, CN1962717A, 2007: pp. 1-3.

20. Waseda, Y., Matsubara, E., Shinoda, K. X-Ray Diffraction Crystallography: Introduction, Examples and Solved Problems Springer 2011: pp. 200-310.

21. Zhu, Y.P., Chen, X. Discussion on Crystallinity Calculated by the Technology of Peak Separation Research and Exploration in Laboratory 03 2010: pp. 41-43. https://doi:10.3969/j.issn.1006-7167.2010.03.013

22. Gert, $\mathbf{S}$. The Physics of Polymers-Concepts for Understanding Their Structures and Behavior, Machine Press, China, 2012: pp. $165-173$.

23. He, M.J., Zhang, H.D., Chen, W.X., Dong, X.X. The Physics of Polymers, Fudan University Press, China, 2005: pp. $153-217$.

24. Pires, R., Laas, H.J. A New Tailor-made Polyisocyanate for Two-pack Waterborne Polyurethane Coatings Surface Coatings International Part B: Coatings Transactions 85 2002: pp. $185-90$. https://doi.org/10.1007/bf02699507

25. Rink, H.P., Mayer, B. Water-based Coatings for Automotive Refinishing Progress in Organic Coatings 34 1998: pp. $175-180$. https://doi.org/10.1016/s0300-9440(98)00038-1 